\title{
Endovascular Treatment of Un-Ruptured Cerebral Aneurysms (Experience by Neurologist)
}

Eman Khedra ${ }^{a}$, Ahmed Bassiony ${ }^{b}$, Hany Zaky-Eldin ${ }^{b}$, Bastawy Fawal ${ }^{c}$, Ahmed Shoyb $^{c}$

(a) Department of Neuropsychiatry, Faculty of Medicine, Assiut University, Assuit, Egypt and the Academic

Director of Neuropsychiatry Department, Faculty of Medicine, Aswan University, Aswan

(b) Department of Neuropsychiatry, Faculty of Medicine, Ain shams University, Cairo,

(c) Department of Neuropsychiatry, Faculty of Medicine, Aswan University, Aswan, Egypt.

Corresponding author: Ahmed Shoyb,email: ahmed.shoyb@yahoo.com

\begin{abstract}
Saccular intracranial aneurysms are localized enlargement lesions of the vasculature, most commonly sited at bifurcation points in the circle of Willis. Un-ruptured intracranial aneurysms (UIA) are a common finding, occurring in about $2 \%$ of the population, making them very probable to be seen by most practitioners, and present a challenge in the recommendations for optimum management and screening. Most aneurysms do not rupture and patients harboring these lesions often remain asymptomatic.

Material and Methods: we recruited 12 patients with un-ruptured intracranial aneurysms that was treated by endovascular intervention and evaluated clinically and angiographically before procedure and 3-6 months after procedure

Results: the mean age of the patients was $51.42 \pm 11.23$ ranging age $23-69$ years. 6 were females and 6 were males. 5 patients $(41.7 \%)$ were hypertensive which was the commonest risk factor in those patients, 6 patients (50\%) had ICA (Internal Carotid Artery) aneurysm.

Conclusion: endovascular therapy of intracranial aneurysms is a safe and effective method of therapy with less morbidity and mortality rates.
\end{abstract}

Keywords: un-ruptured aneurysm, Coiling.

\section{INTRODUCTION}

The prevalence of intracranial aneurysms are about 1 to 5 percent in adult population. Often they will stay asymptomatic during the course of life ${ }^{(\mathbf{1})}$. Rupture of an intracranial aneurysm is the most serious complication that lead to aneurismal subarachnoid hemorrhage (ASAH), which accounts for $5 \%$ to $10 \%$ of all strokes. ASAH causes more morbidity and mortality than other stroke types ${ }^{(2)}$. Un-ruptured aneurysms can often remain asymptomatic (particularly those less than $10 \mathrm{~mm}$ ) or can present with symptoms including headache, seizure, cranial nerve palsies, focal neurologic deficits related to mass effect, and cerebral ischemic events distal to the site of aneurysm due to emboli arising from the aneurysmal $\mathrm{sac}^{(3)}$.

\section{PATIENTS AND METHODS}

We recruited patients who were submitted to endovascular therapy for symptomatic and asymptomatic un-ruptured intracranial saccular aneurysms between august 2018 and august 2019. All patients satisfied the following: un-ruptured intracranial aneurysms presented by mass effect or accidentally discovered $(>5 \mathrm{~mm}$ in anterior circulation, posterior circulation aneurysm and aneurysm in patient with past or family history of subarachnoid hemorrhage).

\section{Ethical approval:}

Written consents were obtained from all patients before the procedures. The study was approved by Aswan University, Faculty of Medicine Ethical Committee. Ethical approval no: ASU 44-1-16.
All patients experienced clinical assessment by NIHSS score on admission and 3-6 months follow up after procedure, brain CT scan, cerebral CT angiography (CTA) or MR angiography (MRA) when necessary, and six vessel digital subtraction cerebral angiography (DSCA) followed by endovascular aneurysmal therapy. Clinical and radiological (3D MRA or DSCA) followup was done 3- 6 months after discharge. A "good" outcome was defined as improved clinical symptoms and angiographically as totally occluded aneurysm.

\section{Technique of intervention and peri-procedural management}

All procedures were done through femoral puncture. Six vessels DSCA was done for all patients. Once saccular cerebral aneurysm was recognized, complete assessment of its angiographic features was done using three-dimension angiography or two-dimension angiography in different projections. Our angiographic assessment aimed to identify the aneurysm site, size, presence of daughter aneurysm arising from the main sac, and presence of branch arising from the aneurysm.

Systemic heparinization was done once the endovascular therapy was decided. Then, selective catheterization of the target vessel (either the internal carotid or the vertebral artery) was done using $6 \mathrm{~F}$ guiding catheter. Using coaxial system, the pathway to the aneurysm was navigated and then the aneurysmal sac was selectively catheterized using micro-catheter and treating it with optimum endovascular method either simple coiling, remodeling technique or flow diversion. 
Successful procedural outcome was well-defined as the target aneurysm having complete angiographic occlusion or residual neck according to Modified Raymond-Roy Classification (MRRC) into; class I (complete obliteration), class II (residual neck), class IIIa (residual aneurysm with contrast within coil interstices), and class IIIb (residual aneurysm with contrast along aneurysm wall) in angiographic appearances. During follow-up, recurrence was defined as recanalization of a volume within the aneurysm; large that need to retreatment with endovascular means ${ }^{4}$.

\section{Statistical Analysis}

Patients' data, aneurysm features and therapeutic outcomes were tested as qualitative or continuous variables, as appropriate. Qualitative data are expressed as numbers and/or percentages. Mean values are presented as the mean $\pm \mathrm{SD}$ and the range. All data were analyzed with the aid of the SPSS version 16.

\section{RESULTS}

Patients' characteristics and initial clinical evaluation are presented in table 1 .
Angiographic evaluation of our patients is shown in table 2.

Procedure outcome (table 3) among our patients 6 patients $(50 \%)$ were treated with simple coiling technique, 5 patients $(41.7 \%)$ were treated with flow diversion stenting and only one patient (8.3\%) was treated by balloon assisted coiling. Out of 12 patients $91.7 \%$ of them (11 patients) had no complication either during or after the procedure. One patient had thrombus formation and vasospasm that was treated by intraarterial injection of antiplatelet and nimodipine,

Clinical follow of the patients 3-6 months after procedure $83.3 \%$ of them (10 patients) clinically improved regarding to NIHSS score, $16.7 \%$ of patients (2 patients) had no clinical improvement.

There was a significant improvement of the mean of scores of NIHSS 3-6 months follow up after procedure ( $\mathrm{p}<0.001)$. 1 . (Mean \pm SD Pre procedure was $2.3 \pm$ 1.452 while post procedure was $0.49 \pm 1.248$ ).

Follow up angiography of those patients showed that $91.7 \%$ of follow up patients (11 patients) had totally occluded aneurysm and only one patient $(8.3 \%)$ had aneurysm recanalization (according to Modified Raymond-Roy Classification (MRRC).

Table 1: Patients characteristics and initial clinical evaluation

\begin{tabular}{|l|l|l|}
\hline Patients character & $n=12$ & $\%$ \\
\hline Sex male & 6 & 50 \\
Female & 6 & 50 \\
\hline Age per years range & $23-69$ & \\
Mean +/- SD & $51.42+/-11.23$ & \\
\hline Risk factors Hypertension & 5 & 41.7 \\
Diabetes mellitus & 3 & 25 \\
Undefined & 4 & 33.3 \\
\hline Clinical presentation $\quad$ Headache & 1 & 8.3 \\
Motor deficit & 2 & 16.8 \\
$3^{\text {rd }}$ nerve palsy & 4 & 33.3 \\
Asymptomatic & 4 & 33.3 \\
Multiple presentation & 1 & 8.3 \\
\hline Initial CT or MRI finding & 6 & 50 \\
Isodense mass lesion & 6 & 50 \\
Free imaging & & \\
\hline
\end{tabular}

Table 2: Angiographic assessment

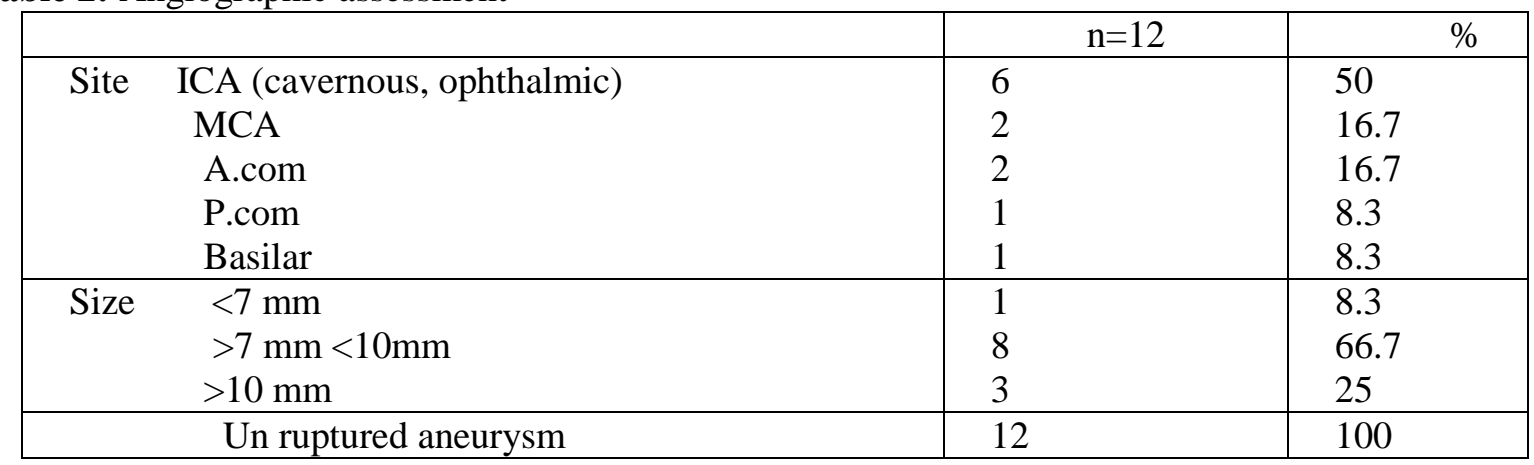


Table 3: Procedure out come

\begin{tabular}{|l|l|l|}
\hline & $\mathrm{n}=12$ & $\%$ \\
\hline Procedure of treatment & 6 & 50 \\
Simple coiling & 1 & 8.3 \\
Balloon assisted coiling & 5 & 41.7 \\
Flow diversion stent & & \\
\hline Complication & 11 & 91.7 \\
No complication & 1 & 8.3 \\
Thrombus formation and vasospasm & & \\
Clinical out come & 10 & 83.3 \\
Improved & 2 & 16.7 \\
Not improved & & \\
Follow up angiography & 11 & 91.7 \\
Totally occluded & 1 & 8.3 \\
Recanalized &
\end{tabular}

\section{DISCUSSION}

The prevalence of intracranial aneurysms (IA) accounts for $5 \%$ in the general population, mostly intracranial aneurysms do not rupture over time, but the risk is size dependent. In the International Study of Un-ruptured Intracranial Aneurysms, the 5-year cumulative risk of rupture was negligible for those measuring $<7 \mathrm{~mm}$. Whereas the risk was $2.6 \%$ and $14.5 \%$ for those sized $7-12 \mathrm{~mm}$, located in the anterior and posterior circulation, respectively. Higher risk for rupture were found with larger sizes ${ }^{5}$.

Un-ruptured intracranial aneurysms may be incidentally discovered as a result of complaints unrelated to the aneurysm or detected as they grow and cause compression on adjacent brain structures ${ }^{6}$. Such compressions include middle cerebral artery aneurysms causing hemiparesis, visual field defect, or seizure, posterior communicating artery or basilar artery aneurysms causing third cranial nerve palsy, cavernous sinus aneurysms causing a cavernous sinus syndrome, basilar distribution aneurysms causing compression of the brainstem, and, on rare occasions, an embolus from the aneurysmal sac causing transient ischemic attack or cerebral infarction due to distal embolisation ${ }^{7}$. Other cranial nerves can be involved including trochlear and abducent nerves and the first division of the trigeminal nerve . $^{8}$.

Optimum management of an un-ruptured intracranial aneurysm should include the comparison of the risk of aneurysmal rupture without any intervention with the risks of surgical clipping or endovascular treatment. The factors that should be considered include ${ }^{9}$, aneurysmal factors, such as location, size, morphology, whether a thrombus exists within the aneurysm, and the presence of a daughter sac or multiple lobes ${ }^{\mathbf{1 0}}$, and patient factors such as age, medical history, history of subarachnoid hemorrhage, and family history of subarachnoid hemorrhage ${ }^{\mathbf{1 1}}$.
The substantiation for treatment of un ruptured IA has been more complex and dependent mainly on the assessment of risk of future spontaneous rupture (between $0.05 \%$ and $3.2 \%$ per year for aneurysms less than $10 \mathrm{~mm}$ and up to $5.5 \%$ per year for large aneurysms) ${ }^{\mathbf{1 2 , 1 3}}$ compared with the risks and efficacy of treatment. In the International Study of Un-ruptured Intracranial Aneurysm, endovascular morbidity and mortality ranged from $7.1 \%$ to $9.8 \%$, whereas surgical morbidity and mortality ranged from $10.1 \%$ to $12.6 \%{ }^{14-17}$.

The 2015 American Heart Association and American Stroke Association guidelines on the management of patients with UIAs recommend intermittent imaging studies at regular intervals to follow up UIAs that are managed conservatively (class $\mathrm{I}$; level of evidence $\mathrm{B})^{\mathbf{1 8}}$. This recommendation is based on the understanding that aneurysmal growth may increase the risk of rupture ${ }^{19}$. A first follow-up study at 6 to 12 months after initial discovery is recommended, followed by subsequent follow-up yearly or every other year (class IIb; level of evidence C). Patients with documented enlargement during follow-up should be offered treatment in the absence of prohibitive comorbidities (class I; level of evidence B). Long term follow-up imaging may be considered after treatment, given the combined risk of aneurysm recurrence and formation of de novo aneurysm (class $\mathrm{IIb}$; level of evidence B). The timing and duration of follow-up is, however, not defined for treated aneurysms as well as untreated aneurysms, and additional investigation has been deemed necessary ${ }^{\mathbf{1 8}}$.

In current study, 12 patients with intracranial aneurysms were treated with complete endovascular occlusion, their age ranged from 23 to 69 years with a mean age 51.42 years. The incidence was equally distributed in both sex. Our results were not consistent with other studies. In study of safety and efficacy of 
endovascular treatment of intracranial aneurysms by coiling with and without stent assistance in 235 cases, $180(76.5 \%)$ were female and $55(23.5 \%)$ were male with patient age ranged between 15 and 86 years, with a mean of 55 years $^{20}$. Hypertension was the commonest risk factor among our patients as 5 patients $(41.7 \%)$ were hypertensive. This result had agreement with other study found that hypertension was the most prevalent risk factor in 13 patients $(41.9 \%)^{\mathbf{2 1}}$.

The angiographic outcome showed complete obliteration in 11 aneurysms (91.7\%), recanalization in one aneurysms $(8.3 \%)$, The immediate angiographic result of the (AMERICA) study showed that 52/100 aneurysms had complete occlusion, and 33/ 100 aneurysms had residual neck and 15/100 aneurysms residual $\mathrm{sac}^{22}$.

\section{CONCLUSION}

Endovascular treatment of un ruptured intracranial aneurysm are issue of debate need good evaluation for risk of rupture and risk of endovascular therapy and more study are in need.

\section{REFERENCES}

1-Qureshi AI, Suarez JI, Parekh PD et al. (1998): Risk factors for multiple intracranial aneurysms. Neurosurgery,43(1):22-6.

2-Rinkel GJ, Algra A (2011): Long-term outcomes of patients with aneurysmal subarachnoid hemorrhage. The Lancet Neurology,10(4):349-56.

3- Raps EC, Rogers JD, Galetta SL et al.(1993): The clinical spectrum of un-ruptured intracranial aneurysms. Arch Neurology ;50:265-268.

4-Mascitelli JR, Moyle H, Oermann EK et al. (2015): An update to the Raymond-Roy Occlusion Classification of intracranial aneurysms treated with coil embolization. $\mathbf{J}$ Neuro-intervention Surg.,7(7):496-502.

5-Connolly Jr ES, Rabinstein AA, Carhuapoma JR et al. (2012): Guidelines for the management of aneurysmal subarachnoid hemorrhage: a guideline for healthcare professionals from the American Heart Association/American Stroke Association. Stroke,43(6):1711-37.

6-Brisman J L, Song J k and Newell D W (2006) :Cerebral aneurysms. The New England Journal of Medicine, 355: 928-939.

7-Broderick J P, Brown R D., Sauerbeck L et al. (2009) :Greater rupture risk for familial as compared to sporadic un-ruptured intracranial aneurysms.Stroke, 40:.1952-1957.

8-Brinjikji W, Rabinstein A A, Nasr D M et al. (2011): Better outcomes with treatment by coiling relative to clipping of un-ruptured intracranial aneurysms in the United States, 2001-2008. American Journal of Neuroradiology, 32:1071-1075.

9-Jakubowski J and Kendall B (1978) :Coincidental aneurysms with tumours of pituitary origin. Journal of Neurology, Neurosurgery \&Psychiatry, 41: 972-979.

10-Connolly E S and Solomon R A (2004): Management of unruptured aneurysms.In Management of Cerebral Aneurysms, pp. 271-285, Saunders, Philadelphia, Pa, USA.

11-King J T, Berlin J A and Flamm E S (1994) :Morbidity and mortality from elective surgery for asymptomatic, un-ruptured, intracranial aneurysms: a meta-analysis. Journal of Neuro- surgery,81:837-842.

12-Krings T, Mandell DM, Tim-Rasmus K (2011): Intracranial aneurysms: from vessel wall pathology to the therapeutic approach. Nat Rev Neurology,7:54759 .

13-Brisman JL, Song JK, Newell DW (2006): Cerebral aneurysms. NEJM., 355:928-39.

14-Schievink WI, Schaid DJ, Michels VV (1995): Familial aneurysmal subarachnoid hemorrhage: a community-based study. J Neurosurgery, 83:426-9

15-Minn R, Wiebers D, Whisnant, J, (1998) Un-ruptured Intracranial aneurysms - risk of rupture and risks of surgical intervention. the International Study of Unruptured Intracranial Aneurysms. NEJM, 339:1725-33.

16-Johnston SC, Wilson CB, Halbach VV (2000): Endovascular and surgical treatment of un-ruptured cerebral aneurysms: comparison of risks. Ann Neurology, 48:119.

17-Meyers PM, Schumacher HC, Higashida RT (2010): Reporting standards for endovascular repair of saccular intracranial cerebral aneurysms. J Neuro-Intervention Surgery, 2:312-23.

18-Thompson BG, Brown RD Jr, Amin-Hanjani S et al. (2015): American Heart Association Stroke Council. Stroke ;46(8):2368-2400.

19-Villablanca JP, Duckwiler GR, Jahan R et al. (2013): Natural history of asymptomatic un-ruptured cerebral aneurysms evaluated at CT angiography: growth and rupture incidence and correlation with epidemiologic risk factors. Radiology,269 (1):258-265.

20-Chalouhi N (2012): Treatment of small ruptured intracranial aneurysms: comparison of surgical and endovascular options. Journal of the American Heart Association, 1(4):e002865.

21-Elewa MK(2018): Endovascular coiling for cerebral aneurysm: single-center experience in Egypt. The Egyptian journal of neurology, psychiatry and neurosurgery, 54(1):33.

22-Fargen KM, Blackburn S, Deshaies EM et al. (2014): Final results of the multicenter, prospective axiom micro FX for endovascular repair of intracranial aneurysm study (AMERICA). J Neurointervention Surgery, 27(1):40-3. 